Journal of Social Sciences 7 (4): 643-648, 2011

ISSN 1549-3652

(C) 2011 Science Publications

\title{
Native Understanding of Participation and Empowerment in Community Development
}

\author{
${ }^{1}$ N. Lyndon, ${ }^{2}$ R. Moorthy, ${ }^{1}$ A.C. Er and ${ }^{1}$ S. Selvadurai \\ ${ }^{1}$ School of Social Development and Environmental Studies, \\ ${ }^{2}$ School of History, Politics and Strategy, \\ Faculty of Social Sciences and Humanities, \\ University Kebangsaan Malaysia, Bangi 43600, Selangor, Malaysia
}

\begin{abstract}
Problem statement: The need for local community is often neglected at macro policy level and it is crucial to engage the native world view. The native view will provide adequate information of the needs and aspirations of the community. The aim of this study is to examine the native understanding of participation and empowerment in community development from the world view of Bidayuh rural community at Serian District of Sarawak. Approach: This study adopts a phenomenology research paradigm. This paradigm focuses on the lived experience of the Bidayuh community which are shaped by their own value and daily life experience. Data was gathered through in-depth interviews conducted with 50 respondents. The native understanding of participation and empowerment was analysed from themes derived from the knowledge, experience, interpretation, action and the reaction of the Bidayuh community world view. Results: The findings show that the native understanding of participation by the Bidayuh community is not just limited to the implementation stage but also involves other stages such as planning, assessment and monitoring. However the natives understand empowerment as the process where an individual or a group are able to use the abilities, skills and capacity of their own. Participation by natives in local programs enables communities to have control over resources, increases engagement and decision making and improves their general wellbeing. When individuals are empowered as a consequence of active participation, the different interests and aspirations of groups can come together towards formulating common goals or finding solutions in the rural context. Conclusion: The aspects of participation and empowerment are the main indicator that must be addressed by the policy makers when drafting new comprehensive plan to address the various issues and the problems faced by rural communities. Future studies should address the impact of the local knowledge, local specific needs and freedom in the effectiveness of community development program to native community.
\end{abstract}

Key words: Phenomenology paradigm, Bidayuh community, community development, rural community, local community, native world, native understanding, depth interviews

\section{INTRODUCTION}

Studies conducted by Simvised et al., (2008), Rashidpour et al., (2010), shows that community development is a structured intervention that gives communities greater control over the conditions that affect their lives. However, this does not solve all the problems faced by a local community (Novel et al., 2011; Theodoropoulou and Kaldis, 2008; Samah et al., 2011). Previous studies also clearly shows that the ineffectiveness of community development program to improve the quality of life of indigenous communities in Malaysia and Sarawak are often associated with the attitude of the planners who failed to understand the needs and the aspirations of the community from their own world view (Novel et al., 2011; Rashidpour et al., 2010; Samah et al., 2011). In addition, the implementation of the objectives of a development program typically highlights two things: Firstly, at the macro structure where the ideas and the understanding of planners or agencies are constructed by scientific world view and secondly, there is a tendency to construct Rostow theories of modernization without taking into consideration the importance of world view, social system and culture of the community itself (Novel et al., 2011; Rahman and Naoroze, 2007; Hoque and

Corresponding Author: Novel Lyndon, School of Social Development and Environmental Studies, Faculty of Social Sciences and Humanities, University Kebangsaan Malaysia, Bangi 43600, Selangor,

Malaysia, Tel: 603-89214212 Fax: 603-89213334 


\section{J. Social Sci., 7 (4): 643-648, 2011}

Itohara, 2009). This situation has led to lack of and neglect of understanding and knowledge about the needs of the community.

In addition, the needs and wants are two different concepts. The needs refer to the specific categories of the universal goals that are relevant to all people in order to survive. Meanwhile, the wants or desire is derived from something that is preferred by the individual and cultural environment (Lavers, 2008). Both parties are said to have a different perception, not only in terms of approach, but also in terms of understanding the concept of poverty itself (Ahmed et al., 2011; Simvised et al., 2008). The program planners often use a more symbolic approach rather than integrative and holistic approach. It is based on the observations with the limitations of study the aspects of process and the direction of change (Theodoropoulou and Kaldis, 2008; D'Silva et al., 2010). On the other hand, the recipient of the development plan is said to have used the approach based on personal experiences, needs and aspirations which are shaped by their own world view (micro-level structure). Even so, in fact each has the same goal to eradicate poverty and improve their quality of life (Simvised et al., 2008). This goal has been the driving force to conduct this study. Some of the researchers also mentioned that the failure of development plans was also associated with several aspects such as the emphasis on top-down approach, which has led to the concentration of power without adequate participation from the community members (Rahman and Naoroze, 2007; Chegini, 2010), a limited understanding of needs and aspirations of the recipient plan (Hoque and Itohara, 2009; Simvised et al., 2008), a weak administrative structure (Ahmed et al., 2011), a shallow and narrow understanding of the conceptual and measurement of poverty (D'Silva et al., 2010), marginalization of knowledge, beliefs and social systems of target groups (Samah et al., 2011; Mok et al., 2007) and finally, aspects of participation and empowering people (Hoque and Itohara, 2009; Rahman and Naoroze, 2007; Chegini, 2010). This is the theoretical gap that would like to explore in this study.

Participation shifts the power of rural development from the planners top-down view to the rural subjects active role in varying stages of planning, implementation and monitoring of rural programs. Participation also allows rural participants to define goals and actions to enhance greater control over their condition. Also participation ensures that it is not means to a process of development but as an end in ensuring long term sustainable rural development.

On the other hand empowerment entails the outcome of participation for rural subjects in capacity building efforts for self-development or group success. The empowerment here actualizes the human potential by raising the conscience of rural subjects of their selfhood that allows them to see their existence in social context. Thus through empowerment of individual and groups, it is hoped these transformation process will diffuse into the rural community at large.

Based on these conceptual underpinnings, the objective of this study is to determine the native understanding of participation and empowerment in community development from the world view of the Bidayuh community in the state of Sarawak, Malaysia.

\section{MATERIALS AND METHODS}

Description of study area: The Bidayuh community mainly lives in the Kuching and Samarahan Divisions, which comprises the districts of Bau, Lundu, Siburan, Penrisen, Padawan and Serian (Novel et al., 2011). These areas are commonly known as the Bidayuh place of origin or Bidayuh Belt. The study was conducted in the districts of Serian, which comprises 261 kampungs or villages. The District of Serian covers an area of 2,040 sq $\mathrm{km}$ consisting of 13 zones with a total population of 80,061 , of which $40,085(50.06 \%)$ are males and 39,976 $(49.9 \%)$ are females (Novel et al., 2011). Majority of the population in this district according to ethnic group are Bidayuh (49,117 or $61.4 \%)$, followed by Iban (12,147 or $15.2 \%)$ Chinese $(10,204$ or $12.8 \%)$ and Malay $(9,519$ or $11.9 \%$ ) (Novel et al., 2011). Out of this, only six zones were the Bidayuh areas, namely Tebedu, Ampungan, Amo, Tebakang, Kedup and Bukar. The study area for this research covers the two zones, which are Tebedu and Kedup where the poverty program was carried out.

Research design: This research utilized the phenomenology paradigm that entails the construction of theories that are grounded in everyday activities, in the language and meaning of social actors. Phenomenology is concerned with the study of experience from the perspective of the individual, 'bracketing' taken-forgranted assumptions and usual ways of perceiving. It is based on idealist ontology and the epistemology of constructionism. To describe and understand social life of rural communities' motives and understanding, the abductive approach as proposed by (Dicks and Pahl, 2011; Iphofen, 2011) were used. This is because it provides native worldview of everyday life. 


\section{J. Social Sci., 7 (4): 643-648, 2011}

Data collection: In this research, an in-depth interview using purposive sampling was carried out on Bidayuh community who were involved in the poverty program in the Tebedu and Kedup zone in Serian District. The sampling was based on their period of years their participation as a participant in poverty program. All of them have indicated that they are involved in the poverty program over the past 10 years since year 2000 . Data were gathered through in-depth interviews with the informants over a period of six months, focusing on the informant's perception of self, life and experience and expressed in his/her own words about the way they understanding the concept of participation and empowerment in community development (Panahi and Malekmohammadi, 2010; Firouzjaie et al., 2007; Ahmed et al., 2011; Mok et al., 2007). Each interview lasted for about one to two hours, depending on the situation. Interviews were transcribed and used to create categories and indexing or coding documents, sorting data to locate patterns and generating typologies. Statements from informants were identified for clarity. Nevertheless, the original meanings were retained. Again, after the categories and sub-categories were developed, each transcription was then reviewed several times for clarity. Interviews with all the informants were conducted in Bidayuh language and later were translated to Malay Language.

In this study, after a sequence of 10 interviews with informants, the data reached saturation after 50 interviews. Data saturation refers to the point where the information becomes redundant as one gets from one interview to another the interview becomes redundant where the same patterns are seen repeatedly (Dicks and Pahl, 2011; Iphofen, 2011). As the interviewing was part of the developmental process, the topic will likely expand as more data are gathered and it was necessary to conduct a second round of interviews with as many of the informants, particularly those who were interviewed in the early stages. The number of secondround interviews will be determined when theoretical saturation has been reached that is when no new categories emerge (Iphofen, 2011; Harvey, 2011). The average age of participants was 45 years as of 2008 . Most are married with at least four children. All of them received secondary school education with at least a Malaysian Certificate of Education (MCE). To reiterate, their selection was based on their experience, understanding and knowledge about the lives of Bidayuh community and their participation in poverty program. In order to protect the confidentiality of the group, each participant has been assigned a fictitious name.
Data analysis: The analysis of qualitative data was carried out based on the narratives obtained from indepth interviews focusing on the differences between men and women in educational attainment. Additional field notes from non-participant observation were also obtained. A sequence of activities was carried out during the analysis are as follows: (i) Data was transcribed from recorded interview of each informants, written in Bahasa Bidayuh, the native language of the researched participants; (ii) The taped interviews were reviewed and examined at least twice before they were transcribed; (iii) Each transcription was reviewed several times and reorganized to provide brief explanation on the categories of differences of men and women in educational attainment; (iv) Process of data cleaning entails making the necessary corrections and excluding any redundancies; (v) The transcription was then translated to English in order to clarify and reduce the influence of researcher's biases; (vi) Involves managing the data by constructing categories into a matrix table, tabulating the findings into a more organized fashion; (vii) Using the themes produced from constant comparative analysis; (viii) Particular quotes were tabulated according to the line numbers that appear in the script.

\section{RESULTS}

Native understanding of participation in community development: Majority of the informants felt that the concept of participation refers to the question of to what extent they are involved in decision-making process, particularly in the planning and implementation stage, together involved in the discussions or meetings, have opportunities to express opinions or ideas submitted by them were heard and fully appreciated by the government. At the same time, they also have control or influence the decisions that were taken. For example, Jikim in fact states that "participation is a process in which folks like me have the opportunity to participate and express opinions or ideas in any decision-making process without the existence of any restrictions or fear of the occurrence. I do not want my name suddenly listed as a recipient of the Rubber Planting Scheme without my consultation". Other informants like Beny, John, Peter, David and Simon also argue that priority should be given to the participant to involve in the decision making process, particularly in the planning stage. Meanwhile, Jagu in his statement noted "our participation in decision-making process is more important compared with technical assistance which is provided by the organizer. We know better what we 
need and what should be given to us in order to uplift our quality of life. The best thing is that let us share our knowledge. The process of discussion making between villagers and government agencies should be two-way. Both parties have opportunities to express their ideas or views either in the process of decision making or in the process of implementation of the program".

Native understanding of empowerment in community development: Most of the informants agree that the empowerment in community development refers to a process when an individual or a group is in the phase in which they are able to use the skills, abilities and capacities of their own. In addition, it also involves the ability to comprehend, interpret the problem and then define the requirements and translate these requirements into the definition of the action through participation in the organization itself. The majority of informants in this study also recognize the key components that might include the ability of individuals to gain more control in determining their lives and the ability to produce idea or ideas that can be shared with practitioners in community development program. Things that are set by Jungki in fact are as follows:

I have been involved in the program for two years. What I want to raise here is not because I am angry with the government. I just think that what the Department of Agriculture should do is to include us when they are designing a program or project that is suitable for our development. I have many ideas and opinions. But the governments agencies never give space for us. We do not want to be just players.

The same view was also expressed by Morin. She has this to say:

My life is more meaningful if I was given the opportunity to empower myself with some kind of training in accordance with the will and the resources available on my own. If I am selected as a participant in the proverty program I like to be empowered. There is no point the government provides training courses to me if $\mathrm{i}$ can't apply and deliver it in my agricultural activities. I would like to be independent rather that looking for help from someone.

Meanwhile, Lin might look at not only on the ability of the material contained in a material, such as equipment, fertilizers, financial resources, production resources like land and machinery but also in the form of power attitudes and skills to interact with others. This is because the attitude and skills to interact with others is an important element in efforts to start a business, find business partners and buyers as well as expanding the business. In addition, it is also used as a primary source for working with the buyer, especially the wholesalers. According to Jampong again, even though the Federal Marketing Authority (FAMA) is helpful, the assistance and help given are limited. In fact, in some instances, the wholesale price offered by FAMA is lower than the prices offered by the middleman for the wholesalers.

There are also some informants who rose about aspects of social capital in an effort to empower the participants'. According to them, social capital refers to the norms, institutions and social relationships that form the quality of social interaction in the community which then allows community members in the community to study together with each other. For example, Linda, believes that social capital should cover aspects such as social support, social relationships, skills and information. These aspects are very important asset for an individual to continue with confident when dealing with the problems faced by them. Thus Anna has suggested that these aspects should be strengthened and given extensive attention to ensure that they are able to increase their income. Michael in his opinion, adding that the aspect of empowering the participants must be multi-dimensional and not confined to one form only. This is because the concept of empowerment refers to the ability to gain more control and ability to develop collective strategies to improve their living standards. Thus, the majority of informants expect that the concept should be explained in detail and not just limited to the level of attendance at meetings and exercise alone.

\section{DISCUSSION}

The need for rural subjects to be actively involved in varying stages, especially at the planning stage and post-implementation stage was critical in view of the typical top-down approach adopted by planners who solicit participation at the implementation stage only. The participants would like to be engaged at early stage such as planning stage where their needs and aspirations, as well as their local knowledge can be incorporated in the goals and realized in the actions of the program. Besides that, by engaging the rural subjects at an early stage the feeling of shared decision making process allows the psychological edge by giving them greater control over their condition. Meanwhile the post-implementation stage too warrants 


\section{J. Social Sci., 7 (4): 643-648, 2011}

greater attention of native participation in assessment and monitoring of programs so as to ensure that the process of participation is not only a means of ensuring rural development but also its ends. Viewing participation as an end in all stages, when achieved, will result in long-term engagement by those involved in the process of solution finding. This approach will enable natives to take charge of their own destiny with adequate awareness and responsibility of their action, coupled with minimal support from external bodies such as state or NGOs. There are many situations in the rural context where instead of doing it alone, participation in group enables everyone to accomplish more. Participation by natives in local programs should be the core principle of community-based rural development that enables communities to have control over resources, that fortify decision-making, increases engagement in development and improves their general wellbeing.

Empowerment is the outcome of active local participation, but is also dependent on institutional support. Social capital and network with informal institutions and formal agencies enable greater capacity building for rural folks. The rural subjects would like to be involved and informed about the rural program so that they can arrive at decision on their own and are in control of their action and at the same time would like to gain skills and training that are practically relevant, that will enable them to be independent.

When individuals are empowered, the different interests and aspirations of groups can voluntarily come together either informally or formally to realize some common goals or find solutions in the rural context.

\section{CONCLUSION}

The aspects of participation and empowerment are the main indicator that must be addressed by the policy makers when drafting new comprehensive plan to address the various issues and the problems faced by rural communities. This is to ensure that the concept of quality of life reflects a more holistic representation of the community's needs and aspirations. The study also shows that the meaning of participation and empowerment in the native community development program was very important in order to determine the quality of life of native community. This is because the meaning of participation and empowerment was the main aspect that represents the feelings of the native to improve their livelihood with minimal effect on existing social structure These understanding will enable a bottom-up view to be incorporated as part of the mainstream discourse of development. Thus a redefinition of mainstream discourse will have greater enabling effect on societies in the margin. Future studies should address the impact of the local knowledge, local specific needs and freedom in the effectiveness of community development program to native community.

\section{ACKNOWLEDGMENT}

This research was supported by Universiti Kebangsaan Malaysia under Research University Grant, Malaysia. The researcher would like to thank University Kebangsaan Malaysia for providing Research University Grant UKM-GGPM-PLW-0182011 which enable the research to carry out smoothly.

\section{REFERENCES}

Ahmed, F., C. Siwar. and N.A.H. Idris, 2011. Contribution of rural women to family income through participation in microcredit: an empirical analysis. Am. J. Applied Sci., 8. 238-245. DOI: 10.3844/ajassp.2011.238.245.

Chegini, M.G., 2010. Study of relation of psychological factors of empowerment and entrepreneurship. Am. J. Econ. Bus. Administrat., 2: 86-89. DOI: 10.3844/ajebasp.2010.86.89.

D'Silva, J.L., H.A.M. Shaffril, J. Uli and B.A. Samah, 2010. Acceptance and sustainability of contract farming among youth in Malaysia. Am. J. Agri. Bio. $\quad$ Sci., 5: 350-356. DOI: 10.3844/ajabssp.2010.350.356

Dicks, B. and K. Pahl, 2011. Multimodality and ethnography: Working at the intersection Qualitative Res., 11: 227-237. DOI: 10.1177/1468794111400682.

Firouzjaie, A.A., H. Sadighi and M.A. Mohammadi, 2007. The influence of social capital on adoption of rural development programs by farmers in the caspian sea region of Iran. Am. J. Agric. Bio. Sci., 2: 15-22. DOI: 10.3844/ajabssp.2007.15.22.

Harvey, W.S., 2011. Strategies for conducting elite interviews. Qualitative Res., 11:431-441. DOI: 10.1177/1468794111404329.

Hoque, M. and Y. Itohara, 2009. Women empowerment through participation in micro-credit programme: A case study from Bangladesh. J. Soc. Sci., 5: 244250. DOI: $10.3844 /$ jssp.2009.244.250.

Iphofen, R., 2011. Ethical decision making in qualitative research. Qualitative Res., 11: 443-446. DOI: $10.1177 / 1468794111404330$.

Lavers, T., 2008. Reconciling the needs and wants of respondents in two rural Ethiopian communities. Soc. Indicators Res., 86: 129-147. DOI: 10.1007/s11205-007-9110-x 
Mok, T.Y., C. Gan and A. Sanyal, 2007. The determinants of urban household poverty in Malaysia. J. Soc. Sci., 3: 190-196. DOI: 10.3844/jssp.2007.190.196

Novel, L., S. Selvadurai, A.C. Er, M.J.M. Fuad and M. Zaidah et al., 2011. Intangible factors influencing gender differences in educational attainment using an abductive research strategy. World Applied Sci. J., 13: 46-52.

Panahi, F. and I. Malekmohammadi, 2010. Lisrel analysis of factors for empowering producers to abolish livelihood poverty through optimizing agricultural water resources management. Am. J. Applied Sci., 5: 7-14. DOI:10.3844/ajabssp.2010.7.14

Rahman, H.M. and K. Naoroze, 2007. Women empowerment through participation in aquaculture: experience of a large-scale technology demonstration project in Bangladesh. J. Soc. Sci., 3: 164-171. DOI: 10.3844/jssp.2007.164.171.
Rashidpour, L., S.J.F. Hosseini, M. Chizari and S.M. Mirdamadi, 2010. The pattern of local communitybased management for sustainable rural development in west azarbaijan province. Am. J. Agri. Bio. Sci., 5: 84-88. DOI: 10.3844/ajabssp.2010.84.88.

Samah, B.A.S., H.A.M. Shaffril, M.A. Hassan and J.L. D'Silva, 2011. Can technology acceptance model be applied on the rural setting: The case of village development and security committee in Malaysia. J. Soc. Sci., 7: 113-119. DOI: 10.3844/jssp.2011.113.119

Simvised, P., S. Chantachon and S. Rittidech, 2008. A study of models of life quality development of isan marginal communities as affected by installation of the solar home system. J. Soc. Sci., 4: 272-274. DOI: 10.3844 jssp.2008.272-274.

Theodoropoulou, H. and P. Kaldis, 2008. Changes in rural areas and regional development. J. Soc. Sci., 4:275-279. DOI: 10.3844/jssp.2008.275-279. 